\title{
Overview on the Development of Aquaculture and Aquafeed Production in Korea
}

\author{
Sung-Sam Kim ${ }^{1}$ and Jeong-Dae Kim ${ }^{2}$ \\ ${ }^{1}$ Aquafeed R\&D Center, CJ CheilJedang Feed Semarang, Batang 51281, Indonesia \\ Email: sungsam.kim@cj.net \\ ${ }^{2}$ College of Animal Life Sciences, Kangwon National University, Chuncheon 24341, South Korea \\ Email: menzang@gmail.com
}

Received: 01 November 2017; Accepted: 20 December 2018

\begin{abstract}
Sung-Sam Kim and Jeong-Dae Kim. 2019. Overview onf the Development of Aquaculture and Aquafeed Production in Korea. Aquacultura Indonesiana, 20 (1): 1-7. According to KOSIS (2018), total landings of capture and culture fisheries in Korea increased from 1,073,000 metric tons (MT) in 1971 to 3,743,000 MT in 2017 mainly due to the development in marine aquaculture practices. During the last four decades, marine aquaculture production in Korea showed around 5-fold increases from 491,000 MT in 1977 to 2,310,000 MT in 2017 recording the value of 2.9 billion USD. Last year, the main production was derived from seaweed $(1,755,630 \mathrm{MT})$, while the aquatic animal production was made from shellfish (428,160 MT), fish (86,400 MT), crustacean (mainly shrimp of 5,100 MT) and others (34,530 MT). Either trash fish or moist pellet based on the raw fish is still being fed to marine culture fish, which is the main obstacle for developing the farming. The present situation and development direction are suggested for the mariculture development in Korea.
\end{abstract}

Keywords: Aquaculture; Extruded pellets; Mariculture; Production; Trash fish

\section{History of Aquaculture}

South Korea has mostly surrounded by sea and has $2,413 \mathrm{~km}$ coastline along three coasts (east, west and south coasts) and its land mass is approximately $100,032 \mathrm{~km} 2$. As capture production mainly from inshore and offshore catches continuously decreased, a great attention has been paid to aquaculture which is now one of the very important sectors in terms of food security, revenue and employment to the country (Yoon, 2008). Aquaculture is mainly divided into two categories, marine and inland cultures.
Mariculture production is composed of seaweed, molluscs, finfish, crustacean and other animals, while inland aquaculture is mostly based on finfish production. According to KOSIS (2018), total value of the fishery production hit a record of 8,614 million dollars in 2017, of which main portion came from inshore catch, followed by mariculture and offshore catch, while inland fishery contributed the least for the record (Table $1)$.

Table 1. Value (million USD) by fishery production category (KOSIS, 2018)

\begin{tabular}{|c|c|c|c|c|c|c|}
\hline \multirow[t]{2}{*}{ Year } & \multicolumn{2}{|c|}{2016} & \multicolumn{2}{|c|}{2017} & $(\mathrm{~B}-\mathrm{A})$ & $\mathrm{RI}^{*}$ \\
\hline & (A) & $\%$ & (B) & $\%$ & & \\
\hline Total & $7,477.1$ & 100.0 & $8,613.8$ & 100.0 & $1,136.7$ & 15.2 \\
\hline Inshore $\mathrm{C}$. & $3,636.2$ & 48.6 & $4,014.1$ & 46.6 & 377.8 & 10.4 \\
\hline Mariculture & $2,345.5$ & 31.4 & $2,951.5$ & 34.3 & 606.0 & 25.8 \\
\hline Offshore C. & $1,077.8$ & 14.4 & $1,192.2$ & 13.8 & 114.4 & 10.6 \\
\hline Inland fishery & 41.8 & 5.6 & 45.6 & 5.3 & 3.84 & 9.2 \\
\hline
\end{tabular}

*Relative increase $(\%)=(\mathrm{B}-\mathrm{A}) / \mathrm{A} \times 100$ 


\section{Aquaculture Species and Production}

In 2017, total fishery landings reached $3,743,000 \mathrm{MT}$, of which $61.7 \%(2,310,000 \mathrm{MT})$ was provided by mariculture corresponding to $34.3 \%$ in terms of total value. Inland fishery production $(36,000$ MT) basically originated from finfish culture represented only $0.9 \%$ of total fishery landings, although it amounted to $5.3 \%$ in terms of value (Figs. 1, 2 and 3).

Seaweed aquaculture began in 1960's and sea mustard (Undaria pinnatifida), kelp (Laminaria spp.) and laver (Porphyra tenera) are the main cultured species in Korea. Seaweed production of 1,756,000 MT ranked first in total mariculture production in 2017. Main species of molluscs include oyster (Crassostrea gigas), mussel (Mytilus edulis) and ark shells (Scapharca broughtonii) which have been cultured since the 1970 's. As the second most important group of mariculture, molluscs of 428,156 MT were produced in 2017. Abalone (Haliotis discus hannai) is now the most important species in terms of production value (Fig. 4). Finfish, the third important production group, is dominated by olive flounder (Paralichthys olivaceus) and rockfish (Sebastes schlegeli), of which artificial seed production techniques were developed in 1990 and 1992, respectively. Since then, substantial culture practices were initiated and the main two species now consist of $80 \%$ of the total of mariculture finfish production. Even though marine finfish production of 86,400 MT is fairly lower than those of seaweed and molluscs, it de facto represents the highest production value among the mariculture groups (Fig. 5). Whiteleg shrimp (Penaeus vannamei) is the sole species being cultured since 2004. Although the production of 5,100 MT is negligible, it ranks seventh in terms of production value (Fig. 4). In addition, sea squirts (Halocynthia roretzi and Styela clava) are also cultured and categorized as others in the current aquaculture species in Korea.

Finfish production in freshwater accounts for more than $80 \%$ of inland fishery production. Main species include Japanese eel (Anguilla japonica), catfish (Silurus asotus) and rainbow trout (Oncorhynchus mykiss). It should be noted that fish farming in Korea was developed with cage culture of common carp (Cyprinus carpio) in artificial lakes since 1984, which was, however, totally disappeared in 2000 with increased public concerns against water pollution. In 2017, main species production was 13,000 MT, 6,300 MT and 3,700 MT for eel, catfish and rainbow trout, respectively (KOSIS, 2018).

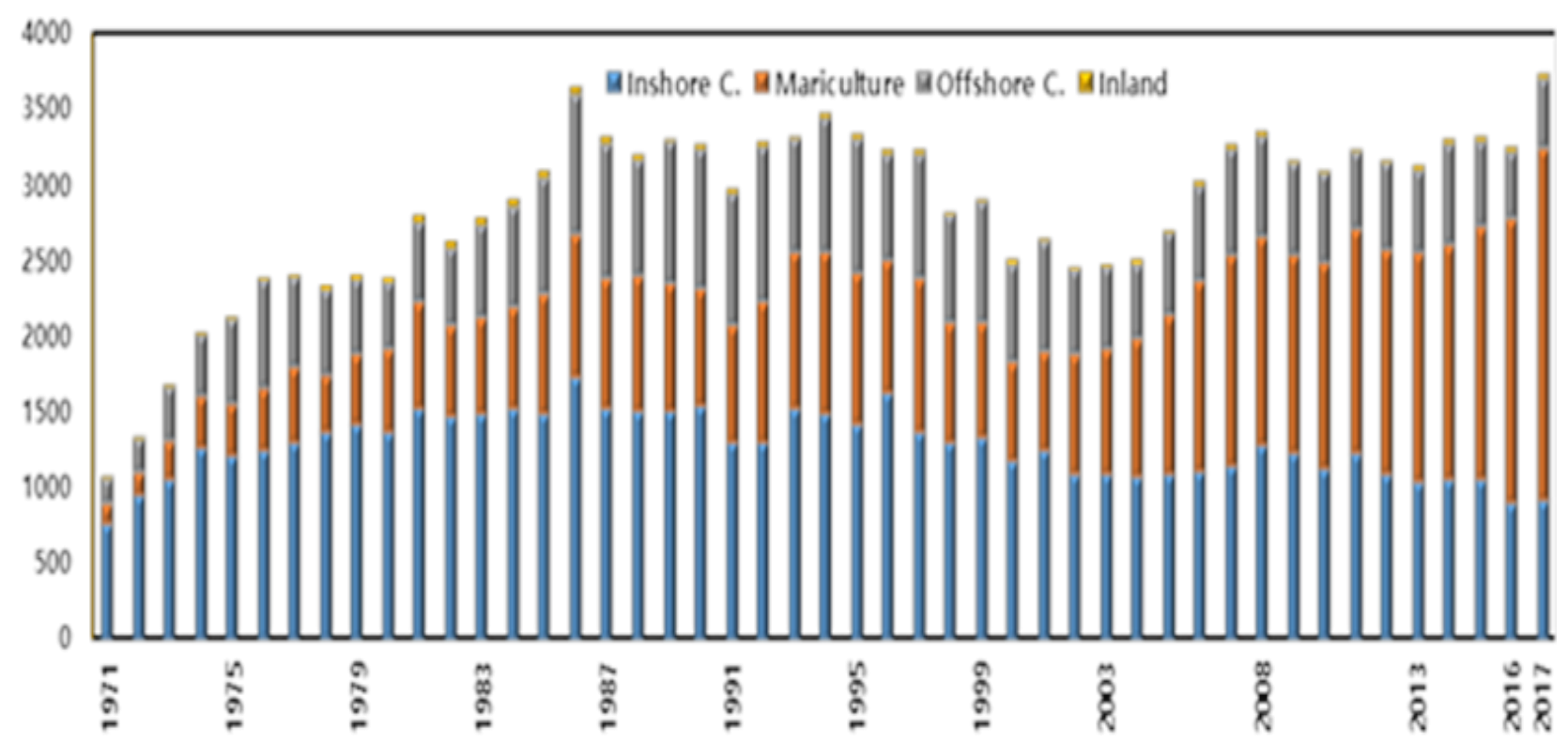

Figure 1 Total Landings (1,000 MT) of Capture and Culture Fisheries in Korea (1972 2017) (KOSIS, 2018; 


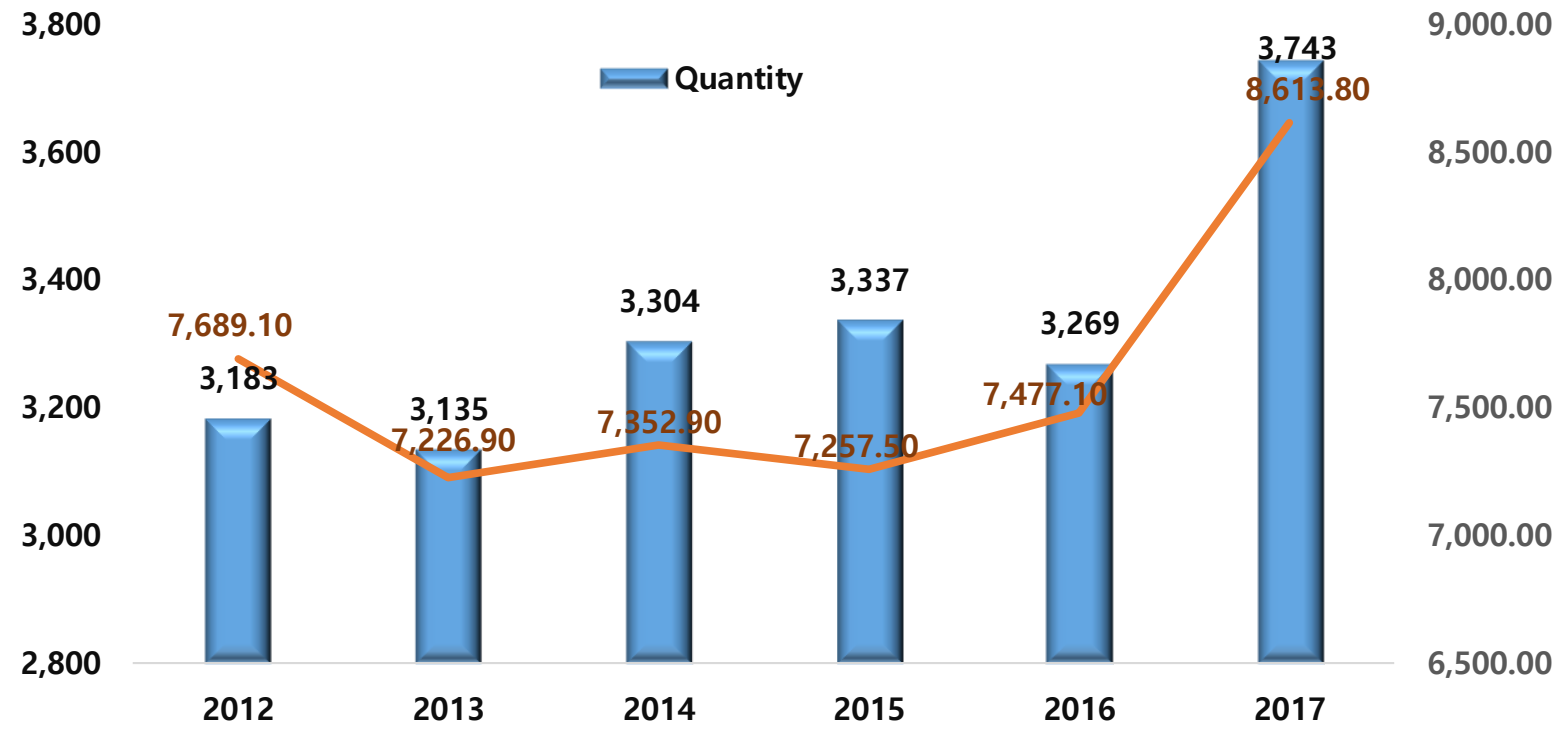

Figure 2 Total Fisheries Landings: quantity (1,000 MT) and value (million USD) (KOSIS,

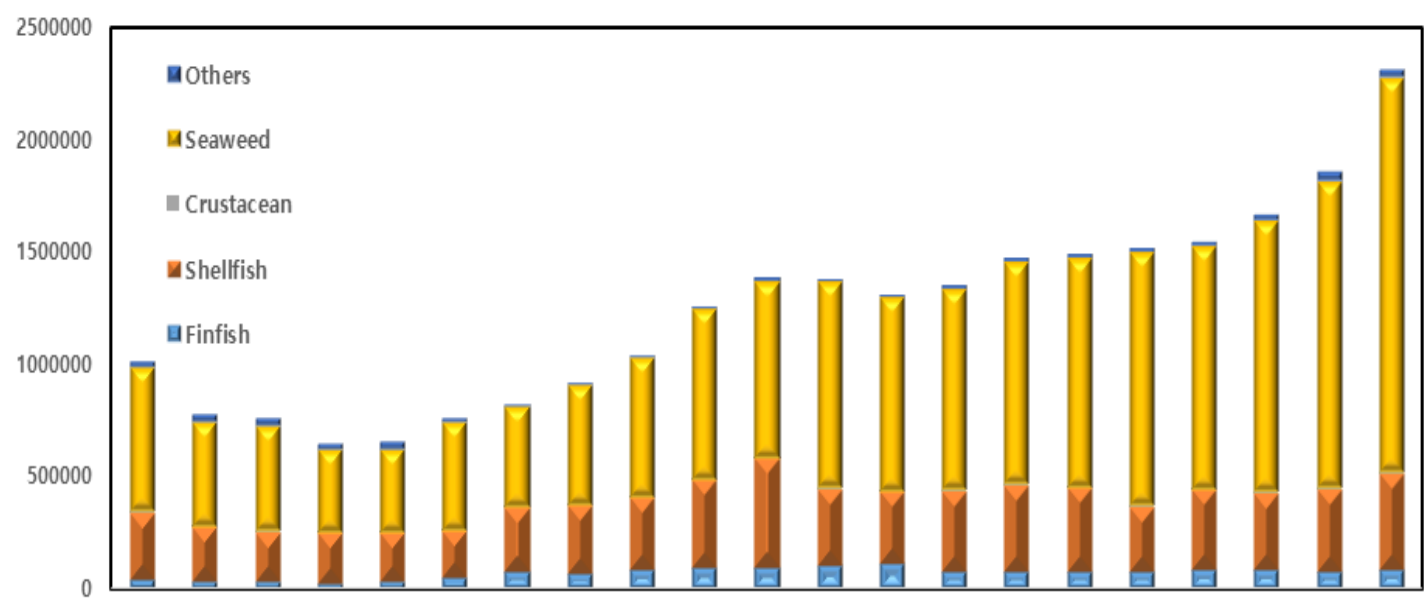

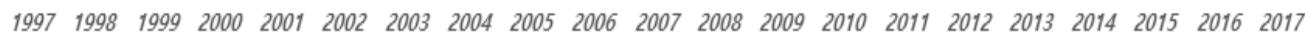

Figure 3 Mariculture Production (MT) in Korea (MOF, 2018).

Value (million USD)

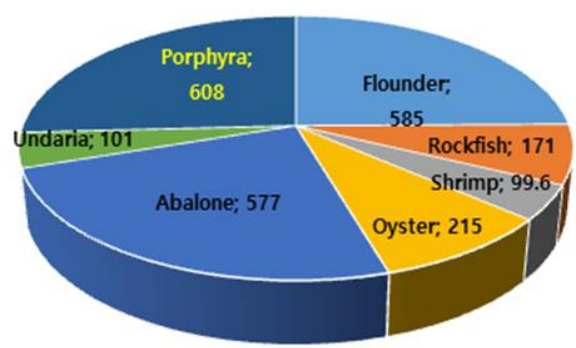

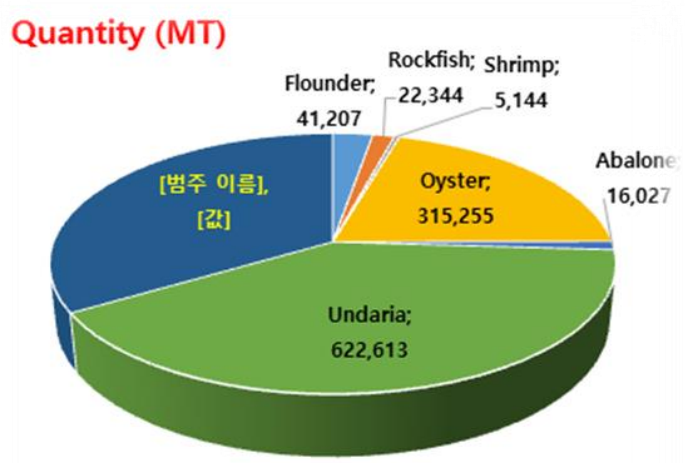

Figure 4 Top 7 species in terms of production value (million USD) and their quantity (MT) in 2017 (KOSIS, 2018). 


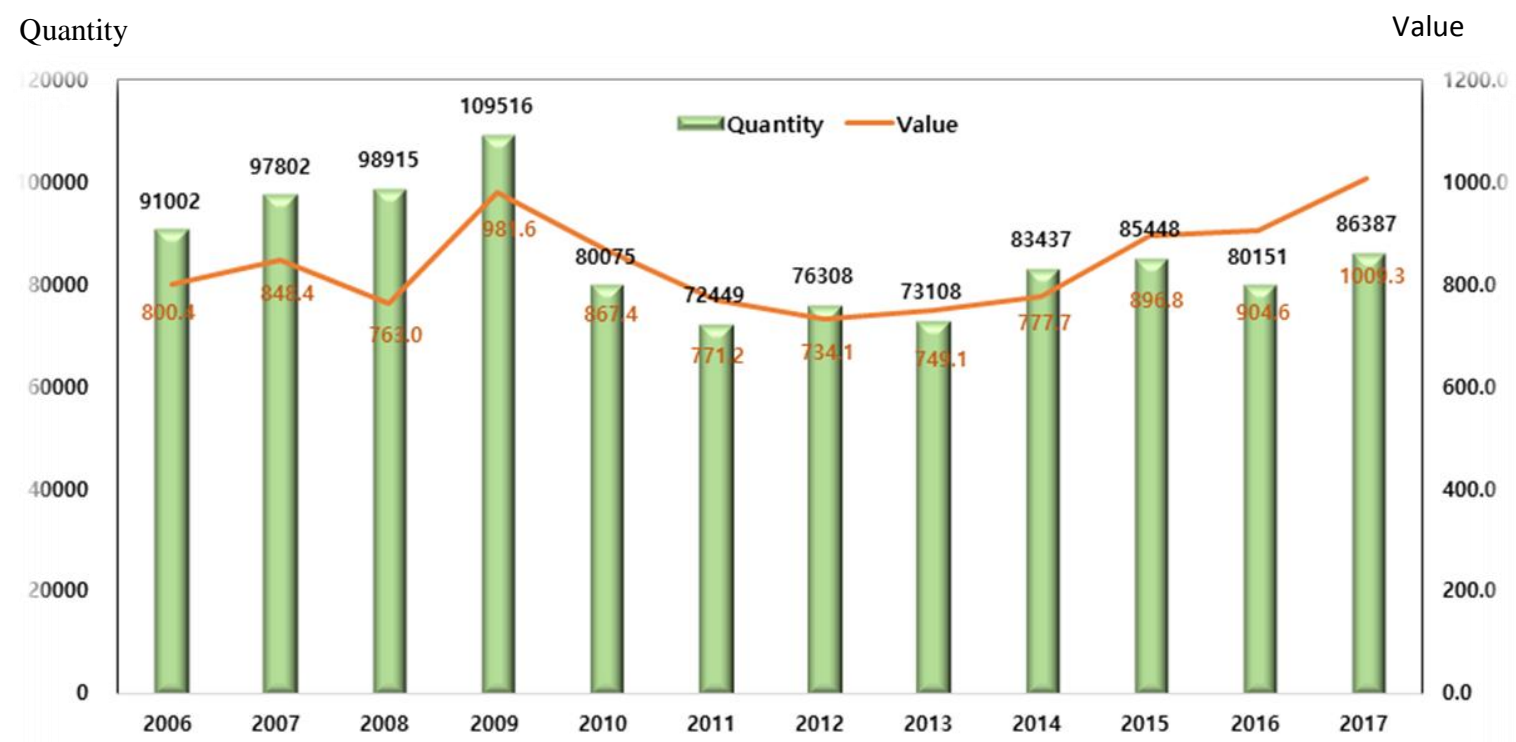

Fig. 5. Mariculture finfish production in Korea (2006 - 2017): quantity (MT) and value (million USD) (KOSIS, 2017, 2018)

\section{Aquafeed Production}

Aquafeed development was initially made for freshwater species including carp, rainbow trout, and eel along with advanced fish farming practices. The highest feed production $(94,846$ MT) for freshwater species was achieved in 1995 , of which $61 \%(58,069 \mathrm{MT})$ were fed to carp. In accordance with an increase in public concerns on carp farming practice against water pollution, most cage farms started taking away from artificial lakes and freshwater feed production, leading to a significant decrease such as 47,948 MT in 1999 with carp diet of only 6,907 MT. Feed production for mariculture fish and shrimp increased from 28,123 MT in 1995 to 52,948 MT in 1999. Since 1999, the feed production for mariculture overtook that for freshwater fish culture. On the other hand, unexpected increase in feed production for eel since 2014 was mainly due to the change in harvesting size from 4-5 fish to $1-2$ fish $/ \mathrm{kg}$ and recorded 28,899 MT in 2017. In 2018 , however, it is anticipated that the production would be decreased to $14,500 \mathrm{MT}$ due to a recent sharp decrease in elver catch. As a whole, total aquafeed production amounted to $151,150 \mathrm{MT}$ in 2017, which were divided into $66.9 \%$ and $33.1 \%$ for marine and freshwater species, respectively (Table 2). On the other hand, aquafeed occupied only $0.78 \%$ of total animal feed production $(18,910,000 \mathrm{MT})$ in 2017.
All diets for cultured fish and shrimp are manufactured to extruded pellet (EP) using the extruder except eel feed, which is made as a powder type mixed with pregelatinized starch al Generally and $10 \%$ powder type of formul in Table 3, total feeds consumption by marine finfish species amounted to 582,776 MT in 2017, of which $85 \%$ were MP. It should be noted that the MP used to produce marine finfish of 86,400 MT corresponding to a half of the inshore catch in 2017 (Fig. 1). On the other hand, 80\% of the MP were distributed to be produced for two species including olive flounder and rockfish, suggesting that mariculture of those species is still in the far distance from the sustainable farming practice. In fact, frequent disease outbreaks, as well as water pollution by wasted feeds, are the main problems raised by feeding the MP (Kim, 2018). Also, the use of the MP threatens the depletion of marine fishery stocks. For example, this phenomenon is much severe in China. According to the recent report (GEA, 2017), approximately 4.95 million MT of trash fish was used in direct feeding aquaculture, of which 66\% (3.24 million MT) were used for mariculture finfish production in 2014. Such trash fish wasere mainly derived from marine catch fishery (GEA, 2017).

Many fish farmers are prepossessed with the idea that a hard type of EP could cause a severe digestive problem like ascites after ingested. Even though a number of the 
experimental results demonstrated that the EP feeding was more advantageous than that of the MP in terms of the production cost (MOF, 2005; NIFS, 2009) as well as water pollution (Kim and Lee, 2000; Kim and Shin, 2006; Kim, 2009; Kim et al., 2011), the use of EP does not show a significant increase until now (Tables 2 and 3 ). When the use of MP is converted to EP (Table 4), it represents 152,400 MT. Given the dead fish and wastage by feeding are considered, an actual amount of the ingested MP would be, however, less than 200,000 MT, corresponding to 61,000 MT of EP. As MP feeding raises public concerns against water pollution, introduction tof pathogenic bacteria and depletion of marine fish stock, legal measurement is now being made to prohibit the use of MP in Korea. Recently, the national project to develop the EP is being conducted to replace the MP for the whole growing period of fish. The research is devoted to decreaseing dietary fish meal using alternative protein sources like land animal by-product meal and plant protein concentrates and to increase palatability and digestibility as well as production income (Kim, 2017).

Table 2. Domestic aquafeed production (2010-2018)

(unit: MT)

\begin{tabular}{|c|c|c|c|c|c|c|c|c|c|c|}
\hline Year & 2010 & 2011 & 2012 & 2013 & 2014 & 2015 & 2016 & 2017 & $2018 \mathrm{E}$ & $17-16$ \\
\hline FW Species total & 33,361 & 28,316 & 28,666 & 26,516 & 31,703 & 39,163 & 39,173 & 49,994 & 35,900 & 10,821 \\
\hline Rainbow trout & 3,552 & 3,862 & 6,305 & 4,437 & 6,383 & 5,435 & 4,876 & 5,290 & 5,440 & 414 \\
\hline Eel & 16,070 & 12,708 & 10,502 & 8,650 & 13,901 & 16,674 & 18,456 & 28,899 & 14,500 & 10,443 \\
\hline Loach & 1,776 & 1,324 & 974 & 1,123 & 65 & 1,295 & 938 & 215 & 300 & -723 \\
\hline Catfish + Carp & 11,252 & 10,093 & 10,706 & 11,406 & 11,314 & 15,127 & 14,693 & 14,742 & 15,100 & 49 \\
\hline Other & 711 & 329 & 179 & 900 & 40 & 632 & 210 & 848 & 560 & 638 \\
\hline SW Species total & 78,359 & 75,587 & 72,710 & 75,818 & 84,747 & 87,677 & 97,738 & 101,156 & 110,530 & 469 \\
\hline Shrimp & 6,216 & 5,571 & 6,289 & 8,113 & 10,633 & 12,579 & 14,926 & 13,176 & 15,250 & $-1,750$ \\
\hline Rockfish + Breams & 19,607 & 26,697 & 25,495 & 26,142 & 26,709 & 26,104 & 31,656 & 36,199 & 36,500 & 4,543 \\
\hline Flounders & 20,028 & 17,498 & 19,021 & 22,270 & 22,840 & 20,296 & 22,381 & 22,663 & 25,780 & 282 \\
\hline Other & 32,508 & 25,821 & 21,905 & 19,293 & 24,565 & 28,698 & 28,775 & 29,118 & 33,000 & 343 \\
\hline Total & 111,720 & 103,903 & 101,376 & 102,334 & 116,450 & 126,840 & 136,911 & 151,150 & 146,430 & 14,239 \\
\hline
\end{tabular}

(Kim, 2018) 
Table 3. Total feed consumption (MT) by marine fish

\begin{tabular}{|c|c|c|c|c|c|c|c|c|}
\hline \multirow{2}{*}{ Species } & \multicolumn{3}{|c|}{2016} & \multicolumn{3}{|c|}{2017} & \multicolumn{2}{|c|}{ 2017-2016 } \\
\hline & Total & MP & $\mathrm{EP}$ & Total & MP & EP &.+- & $\%$ \\
\hline Total & 572,339 & 491,026 & 81,313 & 582,776 & 494,796 & 87,980 & 10,437 & 1.8 \\
\hline Flounder & 251,096 & 230,789 & 20,307 & 246,202 & 226,817 & 19,385 & $-4,894$ & -1.9 \\
\hline Rockfish & 178,114 & 161,183 & 16,932 & 189,228 & 168,312 & 20,916 & 11,114 & 6.2 \\
\hline Black sea bream & 14,413 & 9,875 & 4,538 & 13,843 & 9,207 & 4,636 & -570 & -4.0 \\
\hline Red sea bream & 60,196 & 53,106 & 7,091 & 69,793 & 62,736 & 7,057 & 9,597 & 15.9 \\
\hline Striped beakperch & 8,497 & 5,402 & 3,095 & 7,440 & 3,850 & 3,590 & $-1,057$ & -12.4 \\
\hline Mullet & 19,328 & 422 & 18,905 & 21,877 & 423 & 21,454 & 2,549 & 13.2 \\
\hline Sea bass & 11,710 & 9,678 & 2,032 & 9,097 & 6,982 & 2,115 & $-2,613$ & -22.3 \\
\hline Other & 28,984 & 20,572 & 8,413 & 25,294 & 16,470 & 8,825 & $-3,690$ & -12.7 \\
\hline
\end{tabular}

(KOSIS, 2018)

Table 4. Y2017 MP \& EP Use and EP Production Potential

(unit: MT)

\begin{tabular}{|c|c|c|c|c|c|c|c|}
\hline Species & TFC* & MP & $\%$ & EP use & $\%$ & New EP** & Total EP \\
\hline O flounder & 246,202 & 226,817 & 46 & 19,385 & 22 & 69,860 & 89,245 \\
\hline Rockfish & 189,228 & 168,312 & 34 & 20,916 & 24 & 51,840 & 72,756 \\
\hline Red SB & 69,793 & 62,736 & 13 & 7,057 & 8 & 19,323 & 26,380 \\
\hline Sea bass & 9,097 & 6,982 & 1 & 2,115 & 2 & 2,150 & 4,265 \\
\hline Black SB & 13,843 & 9,207 & 2 & 4,636 & 5 & 2,836 & 7,472 \\
\hline S Beak P & 7,440 & 3,850 & 1 & 3,590 & 4 & 1,186 & 4,776 \\
\hline Mullet & 21,877 & 423 & 0 & 21,454 & 24 & 130 & 21,584 \\
\hline S flounder & 4,461 & 441 & 0 & 4,020 & 5 & 136 & 4,156 \\
\hline Other & 20,835 & 16,028 & 3 & 4,807 & 5 & 4,937 & 9,744 \\
\hline Total & 582,776 & 494,796 & 100 & 87,980 & 100 & 152,397 & 240,377 \\
\hline
\end{tabular}




\section{Obstacles in Aquaculture Development}

As aforementioned, marine finfish culture ranks first in terms of total production value of mariculture. However, the fish culture involves a lot of problems remained to be solved. First of all, the MP should be switched to the EP as soon as possible. The use of trash fish in fish farms accelerates an outbreak of diseases and water pollution as well as the safety problem. A continuous drop in farmgate price urges farmers to gather on a large scale. Urgently needed is a development of new candidate species. Recently, the growing period of flounder was significantly shortened through selective breeding technologies, while rockfish still requires more than 2 years to reach a harvest size of $500 \mathrm{~g}$. Antibiotic use also should be strictly controlled for product safety, although it is still being used at most farms in Korea. Although the standard stocking density should be strictly kept, many farmers do not follow the standard because they believe that $50 \%$ of the stocked seeds are dead.

\section{Conclusion}

As one of the fast growing industry sectors, aquaculture has occupied a significant ranks first among mariculture species groups in terms of production value. However, a sustainable development of fish farming industry could not be achieved without prohibiting the use of the MP. When the MP is totally switched to the EP, the aquafeed industry could open a new market when the MP is totally replaced with EP.

\section{Referense}

GEA (Greenpeace East-Asia). 2017. Research report on China's trash fish fisheries. Greenpeace East-Asia, 42pp.

Hwang, J.W. and D.H. Kim. 2009. An economic feasibility comparison of the extruded pellets and moist pellet on the olive flounder culture farms. J Fish Busin Admin, 40:189-205.

Kim, J.D. and S.B. Lee. 2000. Effects of dietary growth, feed utilization and pollution load of Japanese flounder (Paralicthys olivaceous). An Anim Res Sci, 11:75-84

Kim, J.D. and S.H. Shin. 2006. Growth, feed utilization and nutrient retention of juvenile olive flounder (Paralichthys olivaceus) fed moist, semi-moist and extruded diets. AsianAust J Anim Sci, 19:720-726. https://doi. org/10.5713/ajas.2006.720
Kim, J.D. 2009. An approach to sustainable development of flounder culture industry in Jeju Island: Moist pellet vs. Extruded pellet. An Anim Res Sci, 20:43-48.

Kim, J.D., S.M. Choi and S.J. Shin. 2011. Growth, Feed Utilization and Nutrient Excretions of Slow Growing Flounder (Paralichthys olivaceus) Fed either Moist or Extruded Pellet. An Anim Res Sci, 22:12-18.

Kim, J.D. 2017. Development Direction of Korean Aquafeed. Commemorative Seminar for the foundation of Korean Aquafeed Association. Feb 22, 2017. Laon Convention, Daejeon, Korea.

Kim, J.D. 2018. Asian aquaculture and domestic aquafeed trends. Aquainfo, 12(4):34-45.

KOSIS (Korean Statistical Information Service). 2017. Investigation of fisheries aquaculture production. Retrieved from http : // kosis. $\mathrm{Kr} /$ statHtml/statHtml.do?mode=tab\&orgId=1 01\&tblId=DT_1EZ0013\&vw_cd=MT_ZTIT LE\&list_id=F38\&scrId $=\&$ seqNo=\&lang_mo de=ko\&obj_var_id=\&itm_id=\&conn_path= MT_ZTITLE\&path $=\% 252$ FstatisticsList $\% 25$ 2FstatisticsListIndex.do on Feb 5, 2017

KOSIS (Korean Statistical Information Service). 2018. Investigation of fisheries aquaculture production. Retrieved from http : // kosis .kr / statHtml/statHtml.do?orgId=101\&tblId=DT 1EZ0005\&vw_cd=MT_ZTITLE\&list_id=F3 $8 \&$ seqNo $=\&$ lang_mode $=$ ko\&language $=$ kor $\&$ obj_var_id=\&itm_id=\&conn_path=MT_ZTI TLE on March 19, 2018.

MOF (Ministry of Oceans and Fisheries). 2005. Development of practical feed replacing raw fish-based moist pellet for aquaculture of marine fish. Research Report of Ministry of Oceans and Fisheries, 566pp

NIFS (National Institute of Fisheries Science). 2009. Field study of flounder EP feed in Jeju Island. Research Report of National Institute of Fisheries Science, TR-2009-AQ-002. $174 \mathrm{pp}$. 